\title{
Correction to: Hydrogel-load exosomes derived from dendritic cells improve cardiac function via Treg cells and the polarization of macrophages following myocardial infarction
}

Youming Zhang ${ }^{2 \dagger}$, Zichun $\mathrm{Cai}^{3+}$, Yunli Shen ${ }^{2 \dagger}$, Qizheng Lu ${ }^{2}$, Wei Gao ${ }^{4}$, Xin Zhong ${ }^{4}$, Kang Yao ${ }^{4}$, Jie Yuan ${ }^{4 *}$ and Haibo Liu ${ }^{1 *}$ (D)

\section{Correction to: J Nanobiotechnol 19:271 (2021)}

https://doi.org/10.1186/s12951-021-01016-x

Following publication of the original article [1], the authors identified some mistakes about the affiliations of the authors. The updated "the affiliations of Authors" is given below and the revisions have been highlighted in bold typeface. The affiliation of the first author "Youming Zhang" and the authors "Yunli Shen, Qizheng Lu," should be Affiliation 2 "Department of Cardiology, Shanghai East Hospital, School of Medicine, Tongji University, Shanghai 200092, People's Republic of China." And the affiliation of the author "Zichun Cai" should be Affiliation 3 "Department of Cardiology, Shanghai East Hospital of Clinical Medical College, Nanjing Medical University, Nanjing 211166, People's Republic of China."

The original article has been revised.

\begin{abstract}
Author details
${ }^{1}$ Department of Cardiology, QingPu Branch of Zhongshan Hospital, Fudan University, Shanghai 201700, People's Republic of China. ${ }^{2}$ Department of Cardiology, Shanghai East Hospital, School of Medicine, Tongji University, Shanghai 200092, People's Republic of China. ${ }^{3}$ Department of Cardiology, Shanghai East Hospital of Clinical Medical College, Nanjing Medical University, Nanjing 211166, People's Republic of China. ${ }^{4}$ Shanghai Institute of Cardiovascular Diseases, Zhongshan Hospital, Fudan University, Shanghai 200032, People's Republic of China.
\end{abstract}

Published online: 28 September 2021

Reference

1. Zhang Y, Cai Z, Shen Y, Lu Q, Gao W, Zhong X, Yao K, Yuan J, Liu H. Hydrogel-load exosomes derived from dendritic cells improve cardiac function via Treg cells and the polarization of macrophages following myocardial infarction. J Nanobiotechnol. 2021;19:271. https://doi.org/10. 1186/s12951-021-01016-X.

\section{Publisher's Note}

Springer Nature remains neutral with regard to jurisdictional claims in published maps and institutional affiliations.

The original article can be found online at https://doi.org/10.1186/s12951021-01016-x

\footnotetext{
*Correspondence: yuan.jie@zs-hospital.sh.cn; haiboliu13@fudan.edu.cn †Youming Zhang, Zichun Cai and Yunli Shen contributed equally to this paper

${ }^{1}$ Department of Cardiology, QingPu Branch of Zhongshan Hospital, Fudan University, Shanghai 201700, People's Republic of China

${ }^{4}$ Shanghai Institute of Cardiovascular Diseases, Zhongshan Hospital, Fudan University, Shanghai 200032, People's Republic of China

Full list of author information is available at the end of the article
}

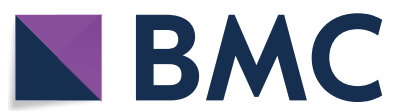

(c) The Author(s) 2021. Open Access This article is licensed under a Creative Commons Attribution 4.0 International License, which permits use, sharing, adaptation, distribution and reproduction in any medium or format, as long as you give appropriate credit to the original author(s) and the source, provide a link to the Creative Commons licence, and indicate if changes were made. The images or other third party material in this article are included in the article's Creative Commons licence, unless indicated otherwise in a credit line to the material. If material is not included in the article's Creative Commons licence and your intended use is not permitted by statutory regulation or exceeds the permitted use, you will need to obtain permission directly from the copyright holder. To view a copy of this licence, visit http://creativecommons.org/licenses/by/4.0/. The Creative Commons Public Domain Dedication waiver (http://creativecommons.org/publicdomain/zero/1.0/) applies to the data made available in this article, unless otherwise stated in a credit line to the data. 